\title{
Influence of Different Post-Core Systems on Impact Stress: a Pilot Study
}

\author{
Yoshihiro Kondoh $^{1}$, Tomotaka Takeda ${ }^{2, *}$, Takamitsu Ozawa ${ }^{2}$, Keishiro Narimatsu $^{2}$, Michiyo \\ Konno $^{2}$, Toshiki Fujii ${ }^{2}$, Chieko Sekiguchi ${ }^{2}$, Kazunori Nakajima ${ }^{2}$, Keiichi Ishigami ${ }^{2}$ and Masahito \\ Shomura $^{3,4}$
}

${ }^{I}$ Department of General Dentistry, Tokyo Dental College Chiba Hospital

${ }^{2}$ Department of Sports Dentistry, Tokyo Dental College

${ }^{3}$ Department of Pediatric Dentistry, Matsumoto Dental University School of Dentistry

${ }^{4}$ Division of Oral Health Promotion, Matsumoto Dental University Graduate School

\begin{abstract}
This pilot study compared impact strain at the core and root surfaces between two different post-core systems.
Materials and Methods: The form of a bovine mandibular front tooth was modified to resemble that of a human maxillary incisor as a test specimen. A cast post and core (Metal PC) and composite resin and glass fiber-reinforced epoxy resin post (Fiber-Resin PC) system were tested. Four gauges were affixed to the buccal and lingual surfaces of the core and root. The specimens were then embedded in a metal mold using dental stone. A pendulum-type device with a pyramid-shaped metal impact object with a titanium alloy head was used to provide 2 different shock forces. Maximum distortion was measured and analyzed.

Results: Distortion at the core at each measurement point and total amount of distortion with Fiber-Resin PC was significantly greater $(\mathrm{p}<0.05)$ than that with Metal PC against both impact forces. On the other hand, distortion at the root at the buccal measurement point with Fiber-Resin PC was significantly less than that with Metal PC against both impact forces. Total distortion was significantly less with Fiber-Resin PC than that with Metal PC against the greater impact shock. Acceleration with Fiber-Resin PC was significantly less than that with Metal PC against both impact forces.
\end{abstract}

Conclusion: Fiber-Resin PC has the potential to protect remaining root against traumatic force. This suggests that a FiberResin PC is more suitable for non-vital teeth against not only occlusal but also traumatic impact force.

Keywords: Acceleration, distortion, glass fiber-reinforced epoxy resin post, impact force, post-core system, root.

\section{INTRODUCTION}

Most endodontically treated teeth are restored with some kind of prosthesis such as a crown or bridge after application of a post-core system. Teeth which received post-core restorations were weaker (Fig. 1) than intact teeth [1]. However, the material used for post-core treatment significantly affects the fracture resistance of the tooth. A metal post-core system is inferior to a nonmetal post-core system in terms of root preservation, showing lower fracture strength and making rerestoration more difficult [2-5]. That is, secondary root fracture can easily occur in teeth treated with a metallic postcore due to the difference in modulus of elasticity [6-8] with that of dentin and deficiency in adhesion strength. Tooth extraction has to be eventually performed in most such cases of root fracture, indicating the need to prevent such injuries from occurring in the first place.

*Address correspondence to this author at the Department of Sports Dentistry, Tokyo Dental College, 1-2-2, Masago, Mihama-ku, Chiba, 261-8502, Japan; Tel: +81432703605; Fax: +81432703609;

E-mail: ttakeda@tdc.ac.jp
Currently, materials with a Young's modulus similar to that of dentin are usually used in the restoration of endodontically treated teeth $[9,10]$. Glass fiber-reinforced epoxy resin posts, resin cements and some composite resins all fall into this category. The in vivo use of these materials may significantly reinforce residual tooth structure (Fig. 2) and therefore reduce the risk of fracture and debonding [11-13]

One study [14], however, reported that failure significantly increased as load angle approached parallelism with the long axis in teeth restored with cast-post and cores and crowns. Moreover, maxillary anterior teeth are at high risk of traumatic root fracture, even when intact, due to frequent subjection to impact from horizontal forces [15-18]. Therefore, when such teeth are treated with a post-core and crown or an abutment for a bridge, they become even more susceptible to damage from impact force.

To the best of our knowledge, fracture resistance in teeth treated with a post-core system has only been examined using static loading [2-7, 9, 10, 19-21] or finite element analysis that assumed occlusal force $[7,22]$. That is to say, much remains to be clarified regarding the relationship between dynamic loading and traumatic injury. And little is known, in 

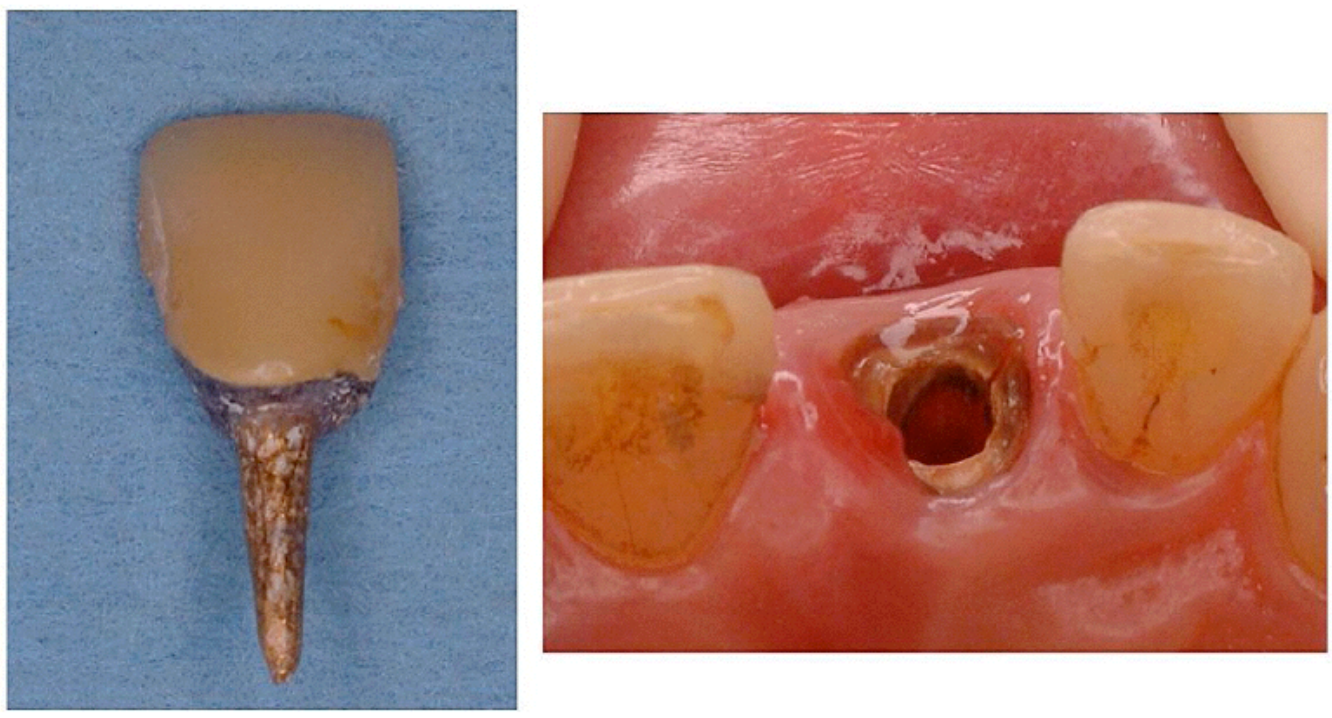

Fig. (1). Teeth which received post-core restorations thought to be weak.
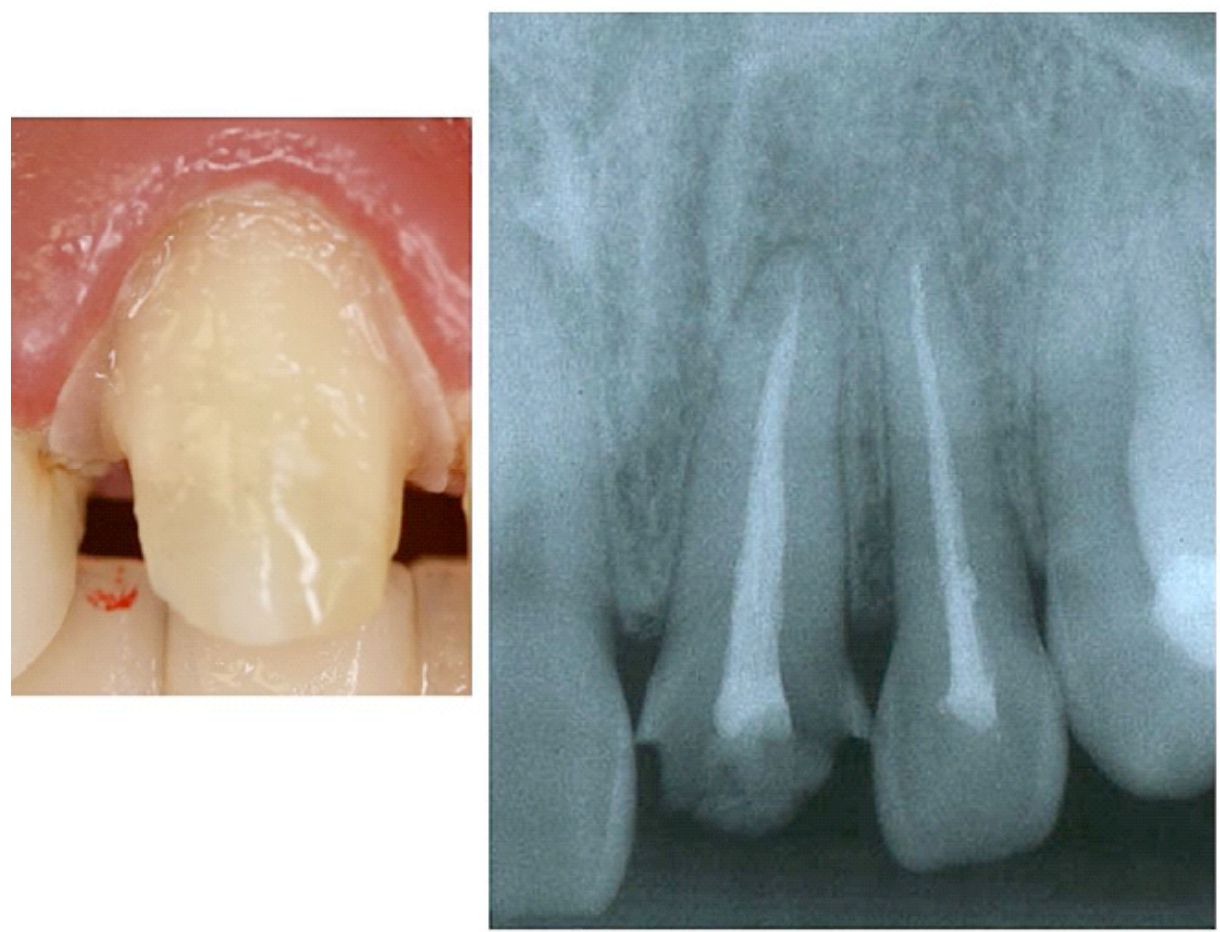

Fig. (2). Use of composite resin and glass fiber-reinforced epoxy resin post system may reinforce residual tooth structure.

particular, regarding traumatic injury caused by dynamic or impact loading.

The purpose of this study was to compare impactinduced strain on the core and root surfaces between teeth treated with a conventional cast post-core system (Metal PC) and those treated with a glass fiber-reinforced epoxy resin post and composite resin post-core system (Fiber-Resin PC).

\section{MATERIALS AND METHODS}

As a specimen, a bovine (about 20 weeks of age) mandibular anterior tooth with a narrow pulp cavity was modified to resemble a human upper incisor root in form (Fig. 2) using the CELAY system (MIKRONA Technologie AG, Spreitenbach, Switzerland). To obtain a root model, the crown (D18D-500H, Nisshin, Co., Ltd, Tokyo, Japan) was then removed at approximately $2 \mathrm{~mm}$ above the cementenamel junction [21]. Post spaces of approximately $8 \mathrm{~mm}$ in length were prepared using a \#3 post drill $(1.5 \mathrm{~mm}$ in diameter; taper, 1/20 Nikkosha, Tokyo, Japan). The roots were treated with a Metal PC or a Fiber-Resin PC.

An impression for Metal PC was taken from the root using hydrophilic vinyl polysiloxane impression materials (EXAFINE Regular Type and Regular Hard Type, GC Co., Japan) and poured dental stone (New FUJIROCK, GC Co., Japan). The Metal PC was fabricated by the usual procedure: a wax pattern was taken, followed by investing and casting with gold-silver-palladium alloy (Castwell MC 12\% Gold, GC Co., Japan) and cementing (Super-Bond C\&B, Sun 


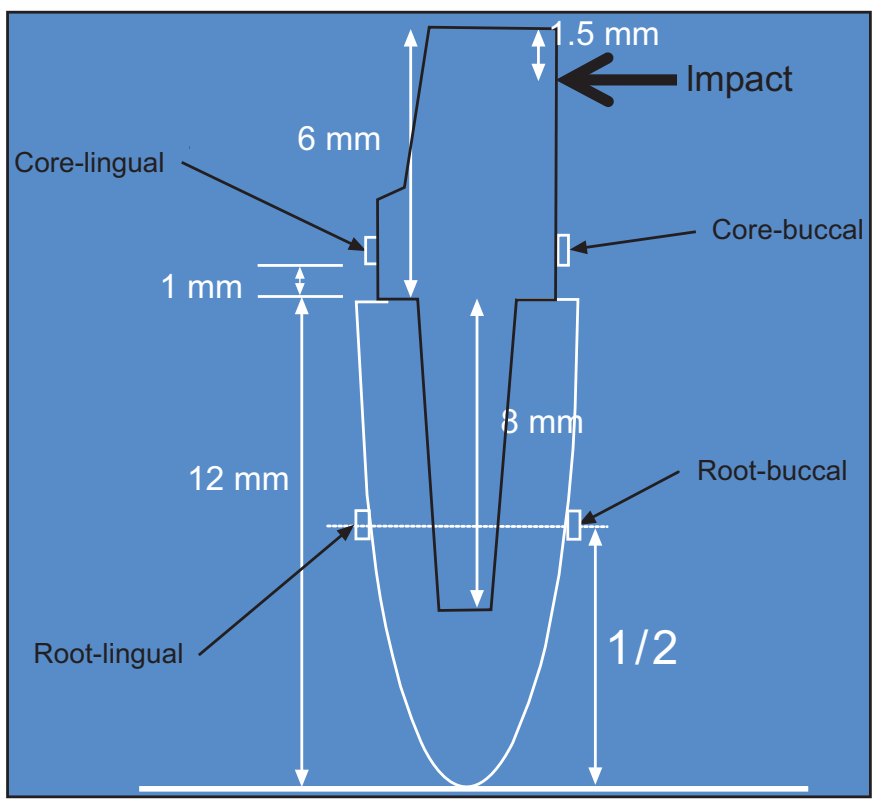

Fig. (3). Four strain gauges in total were affixed to core and root on labial and lingual surfaces.

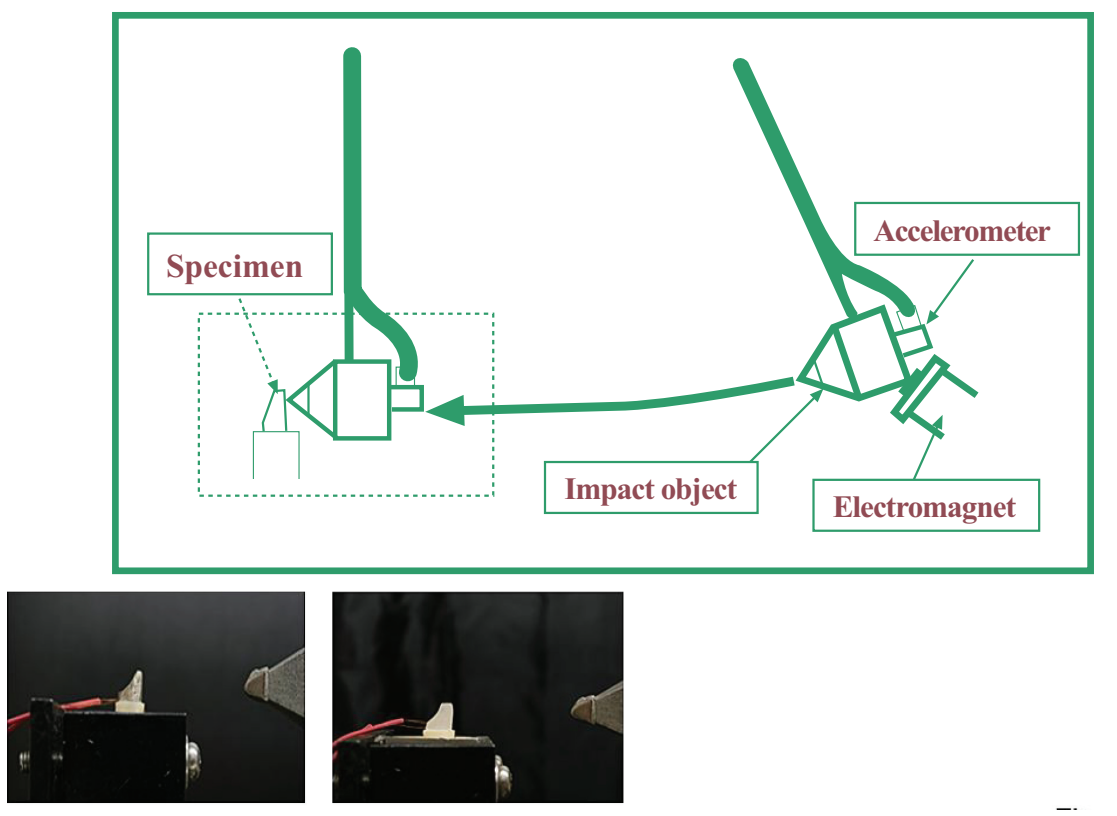

Fig. (4). Pendulum-type impact device comprising pyramid-shaped metal impact object with titanium alloy head affixed to an accelerometer.

Medical Co., Japan). The height of the core was approximately $6 \mathrm{~mm}$. The buccal surface of the impact area was flattened to allow precise application of impact. A glass fiber-reinforced epoxy resin post (FibreKor Post, $1.25 \mathrm{~mm}$ in diameter, PENTRON ${ }^{\circledR}$ JAPAN INC. Japan.) was cemented in and the coronal aspect built up using a dual-cured composite resin cement (CLEARFIL DC Core, Kuraray Medical Co., Japan) according to the manufacturer's instructions. A transparent polycarbonate thermoformed resin blank of 1 $\mathrm{mm}$ in thickness (Biolit D Dreve-Dentamid GMBH, Unna, Germany) was applied to the original metal PC to obtain a mold, which was used to create a core for the Fiber-Resin PC. The posts extended the full length of the core height.
Four strain gauges (SKF-20565; Kyowa Electronic Instruments Co., Ltd, Tokyo, Japan) were affixed to the core and the labial and lingual surfaces of the root (Fig. 3). Next, the specimens were embedded in an aluminum container $(30 \times 20 \times 20 \mathrm{~mm})$ using dental stone (NEW FUJIROCK, GC Co., Japan) and kept dry until mounted in a fixation stand for the impact test. Impact was delivered by means of a pendulum-type device and measurement performed in a manner similar to that described in our earlier studies (Fig. 4) [2327]. Briefly, a pyramid-shaped metal impact object with a titanium alloy head (approximately $600 \mathrm{~g}$ ) affixed to an accelerometer (AS-A YG-2768 100G, Kyowa, Tokyo, Japan) was employed and 12 impacts applied to each specimen. The 

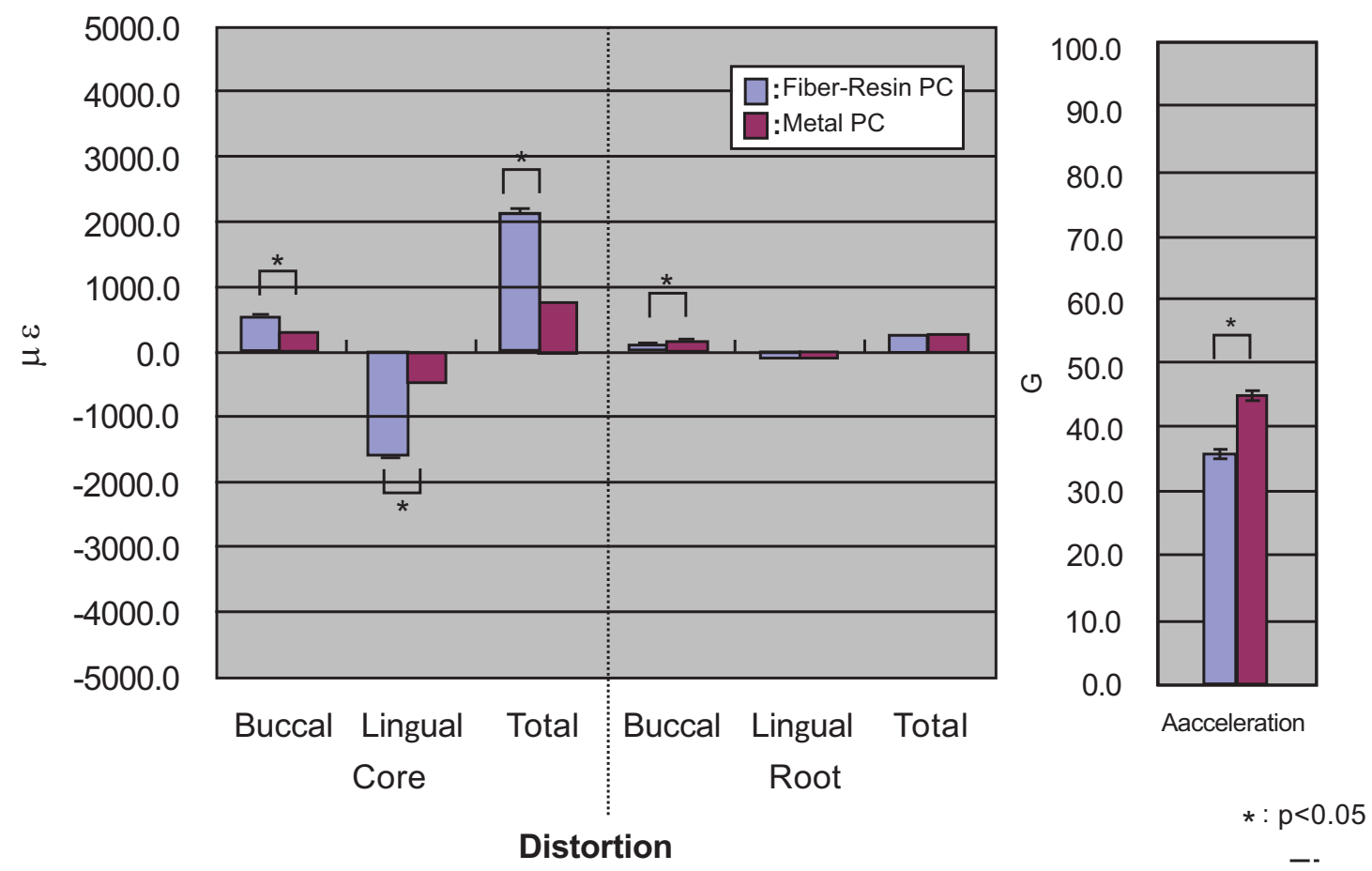

Fig. (5). Strain with Fiber-Resin PC or Metal PC at four measurement points; total amount of distortion at core and root surfaces with each system and acceleration over $50 \mathrm{~mm}$ impact distance.

impact point was adjusted using the XYZ axis Pack and Pinion Dovetail Stage (TAR-70135, Sigma Koki, Tokyo, Japan) attached to the fixation stand so that the impact object would hit the buccal surface of the core at precisely $1.5 \mathrm{~mm}$ from the upper edge. Impact distances were 50 and $100 \mathrm{~mm}$ (potential energy: 14.7 and $58.8 \mathrm{~g} \mathrm{~m}^{2} / \mathrm{s}^{2}$, respectively) from the surface. All tests were conducted in an air-conditioned room at $25^{\circ} \mathrm{C}$. Mechanical forces recorded by the strain gauges and accelerometer were amplified, converted into an electric output voltage and stored as data with a memory recorder analyzer (EDX-1500A, Kyowa). The data were then analyzed with the data analysis software DAS-100A (Kyowa). The mean and standard deviation were calculated for maximum strain and acceleration at each measurement point. The absolute value at each measurement point was determined and totaled for the core and root surfaces. The Kruskal-Wallis and Steel-Dwass multiple comparison tests were used for the statistical analysis $(p<0.05)$ using SPSS (SPSS Ver.11, Japan Inc., Tokyo, Japan).

\section{RESULT}

Strain at each of the four measurement points with Metal PC or Fiber-Resin PC, total amount of strain at the core and root surfaces, and acceleration at $50 \mathrm{~mm}$ impact distance are shown in Fig. (5). The same data for an impact distance of $100 \mathrm{~mm}$ are shown in Fig. (6). The results of the KruskalWallis and Steel-Dwass multiple comparison tests $(\mathrm{p}<0.05)$ are also shown in these figures.

At $50 \mathrm{~mm}$ impact distance (Fig. 5): significantly greater distortion was observed with Fiber-Resin PC (524.6 \pm 38.9 $\mu \varepsilon)$ than with Metal PC $(293.8 \pm 9.6 \mu \varepsilon)$ at the buccal surface of the core; significantly greater distortion was observed with Fiber-Resin PC $(-1598.3 \pm 29.7 \mu \varepsilon)$ than with Metal PC
$(-452.5 \pm 18.0 \mu \varepsilon)$ at the lingual surface of the core; significantly less distortion was observed with Fiber-Resin PC $(101.7 \pm 4.4 \mu \varepsilon)$ than with Metal PC $(132.5 \pm 6.2 \mu \varepsilon)$ at the buccal surface of the root; almost the same level of distortion was observed between Fiber-Resin PC $(-125.0 \pm 4.8 \mu \varepsilon)$ and Metal PC $(-120.0 \pm 11.1 \mu \varepsilon)$ at the lingual surface of the root. In terms of total amount of distortion at the core, significantly greater distortion was observed with Fiber-Resin $\mathrm{PC}(2122.9 \pm 54.0 \mu \varepsilon)$ than with Metal PC $(746.3 \pm 25.4 \mu \varepsilon)$. On the other hand, less distortion was observed with FiberResin PC $(226.6 \pm 8.3 \mu \varepsilon)$ than with Metal PC $(252.5 \pm 14.5$ $\mu \varepsilon)$ at the root. Significantly less impact object acceleration was observed with Fiber-Resin PC $(35.8 \pm 0.8 \mathrm{G})$ than with Metal PC $(45.1 \pm 0.8 \mathrm{G})$.

At $100 \mathrm{~mm}$ impact distance (Fig. 6): significantly greater distortion was observed with Fiber-Resin PC (631.7 \pm 38.0 $\mu \varepsilon)$ than with Metal PC $(495.4 \pm 40.5 \mu \varepsilon)$ at the buccal surface of the core; significantly greater distortion was observed with Fiber-Resin PC $(-3103.3 \pm 121.6 \mu \varepsilon)$ than with Metal $\mathrm{PC}(-881.3 \pm 41.3 \mu \varepsilon)$ at the lingual surface of the core; significantly less distortion was observed with Fiber-Resin PC $(185.4 \pm 6.2 \mu \varepsilon)$ than with Metal PC $(360.4 \pm 32.9 \mu \varepsilon)$ at the buccal surface of the root; almost the same level of distortion was observed between Fiber-Resin PC $(-218.3 \pm 9.4 \mu \varepsilon)$ and Metal PC $(-229.2 \pm 8.7 \mu \varepsilon)$ at the lingual surface of the root. In terms of total amount of strain at the core, significantly greater distortion was observed with Fiber-Resin PC (3735.0 $\pm 135.2 \mu \varepsilon)$ than with Metal PC $(1376.7 \pm 75.1 \mu \varepsilon)$. On the other hand, significantly less distortion was observed with Fiber-Resin PC $(403.8 \pm 13.7 \mu \varepsilon)$ than with Metal PC $(589.6$ $\pm 34.9 \mu \varepsilon)$ at the root. Significantly less acceleration of impact object was observed with Fiber-Resin PC $(65.7 \pm 1.6 \mathrm{G})$ than with Metal PC $(83.9 \pm 3.5 \mathrm{G})$. 

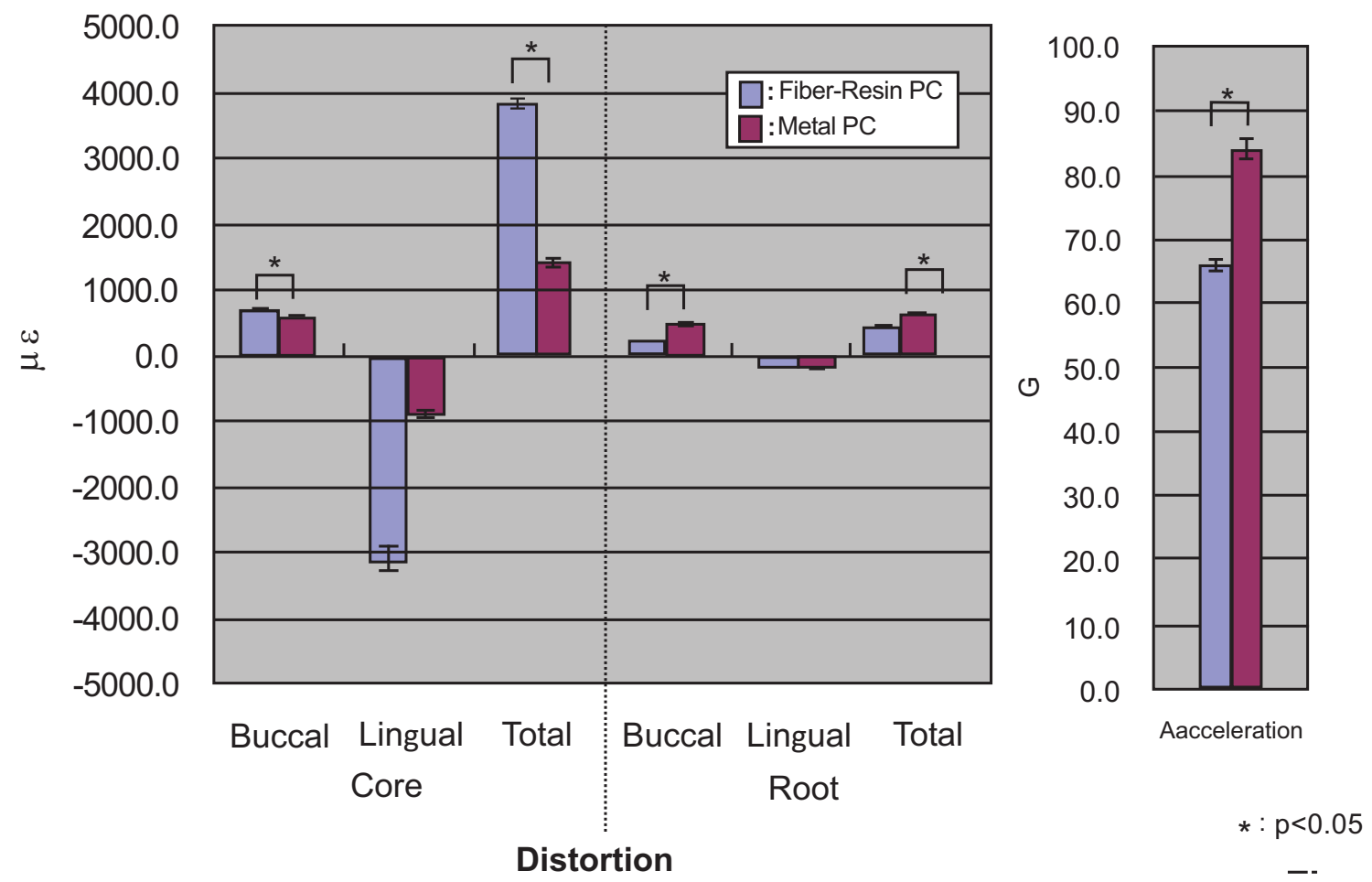

Fig. (6). Strain with Fiber-Resin PC or Metal PC at four measurement points; total amount of distortion at core and root surfaces with each system and acceleration over $100 \mathrm{~mm}$ impact distance.

Effect of impact distance: in terms of total amount of strain at each of the four measurement points in Metal PC or Fiber-Resin PC at the core and root surfaces, impact object acceleration appeared to increase as impact distance lengthened.

\section{DISCUSSION}

The results of the present study demonstrated that the buccal surface showed stretch strain (+ values) and the lingual surface compression strain (- values) at both the core and root in both Metal and Fiber-Resin PCs. Stretch strain at the buccal surface and compression strain at the lingual surface were observed in both core and root as impact was applied to a point superior to the measurement sites.

The main findings of this study were 1) that strain at the core with Fiber-Resin PC was significantly greater than that with Metal PC at each measurement point, and 2) that total amount of strain against both impact forces was significantly greater with Fiber-Resin PC. On the other hand, strain at the root with Fiber-Resin PC tended to be less than that with Metal PC. Furthermore, Fiber-Resin PC showed significantly less impact object acceleration than Metal PC. One possible explanation for this is that the modulus of elasticity of FiberResin PC is lower than that of Metal PC, with a value close to that of dentin [6-8], and that the modulus of elasticity of a glass fiber-reinforced epoxy resin post and composite resin core is equal to that of composite resin itself according to a three-point bending test [5]. Therefore, as strain at the core increases, strain at the root diminishes. Moreover, the greater core distortion observed with Fiber-Resin PC might result in higher energy absorption, resulting in a reduction in impact object acceleration. These results showing superior stress reduction with Fiber-Resin PC than with Metal PC agree with those of earlier reports [2-5].

The results of the present study showed that Fiber-Resin $\mathrm{PC}$ reduced impact distortion in the treated tooth at the root, suggesting that a Fiber-Resin PC can absorb impacted energy to some degree. Impact force is a force applied to a target together with a change in speed over a short duration of time. Generally speaking, the power is very large and duration very short. Additionally, total power is invariable, both before and after impact. Therefore, when impact power is applied to teeth, there are two quite different potential results. If the energy is not great enough to damage the tooth, it is consumed by the viscosity and shock absorption characteristics of the tooth, artificial material or surrounding tissue. When the energy is much greater, however, it becomes destructive, damaging the tooth and resulting in dislocation or fracture of tooth or other tissues [28]. Therefore, the energy absorption capacity of a Fiber-Resin PC is a major merit. Accordingly, a Fiber-Resin PC can protect a remaining root against traumatic forces. Therefore, from the viewpoint of preservation of remaining teeth from impact, a Fiber-Resin $\mathrm{PC}$ is more suitable for non-vital teeth against not only static power but also impact force.

However, some studies have reported that there is a high risk of root fracture, even with a Fiber-Resin PC [4, 29]. Further study is needed to clarify the effect of different postcore systems on fracture resistance and mode of failure.

The aim of this pilot study was to compare impact strain at the core and root surfaces between two different post-core systems. In further study, the following factors need to be taken into consideration: differences in materials used in the 
systems currently being marketed [5, 30]; the bonding strength of composite resin, post material and cement $[8,12$, $31,32]$; the effect of internal bleaching [33]; differences in composite resin for core or post, even when from the same manufacturer; differences in prefabricated post type (glass fiber, carbon fiber, quartz fiber, carbon-quartz fiber, etc.); difference in length of post [6]; length of glass fiberreinforced epoxy resin post [20]; difference in material of metal core-post; the amount, thickness, and strength of remaining tooth structure [5]; the presence and height of a ferrule [20]; the amount of alveolar bone [6]; the type of tooth and embedded material tested $[6,20]$; the presence and type of final restoration [5, 34]; use of a bridge abutment; preserving conditions and effect of thermal cycling [35]; the number of samples, and so on. In addition, strain and acceleration with a Metal PC or Fiber-Resin PC were affected by impact distance or power and impact object in a variety of sports [27]. An increase in impact distance increases destructive energy, and a difference in impact object affects impact shock characteristics. A mouthguard reduces impact energy in collision or contact. Therefore, in further study, it is necessary to investigate the effect of a mouthguard on impact absorption from the sports dentistry viewpoint.

\section{CONCLUSION}

The present pilot study compared impact strain at the core and root surfaces between two different post-core systems, Fiber-Resin PC and Metal PC.

Within the limitations of this laboratory study, strain at the core with Fiber-Resin PC resulted in significantly larger distortion than that with Metal PC, while strain at the root with Fiber-Resin PC yielded less distortion than that with Metal PC against two different impact forces. These results indicate that a Fiber-Resin PC has the potential to protect remaining root against traumatic force. This suggests that a Fiber-Resin PC is more suitable for non-vital teeth against not only occlusal but also traumatic impact force.

\section{CONFLICT OF INTEREST}

The authors confirm that this article content has no conflicts of interest.

\section{ACKNOWLEDGEMENTS}

The authors are indebted to Mr. Koji Otsu, Tokyo, Japan, for his assistance with the measurements. We would also like to thank Associate Professor Jeremy Williams, Tokyo Dental College, for his assistance with the English of the manuscript.

\section{REFERENCES}

[1] Dean JP, Jeansonne BG, Sarkar N. In vitro evaluation of a carbon glass fiber-reinforced epoxy resin post. J Endod 1998; 24: 807-10.

[2] Barjau-Escribano A, Sancho-Bru JL, Forner-Navarro L, et al. Influence of prefabricated post material on restored teeth: fracture strength and stress distribution. Oper Dent 2006; 31: 47-54.

[3] Varvara G, Perinetti G, Di Iorio D, et al. In vitro evaluation of fracture resistance and failure mode of internally restored endodontically treated maxillary incisors with differing heights of residual dentin. J Prosthet Dent 2007; 98: 365-72.

[4] Fukui Y, Komada W, Yoshida K, et al. Effect of reinforcement with resin composite on fracture strength of structurally compromised roots. Dent Mater J 2009; 28: 602-9.
[5] Sasaki K. Reinforcement of Endodontically Treated Teeth with Flared Root Canals Using Composite resin Cores with Glass fiberreinforced epoxy resin posts and a Sleeve. Ann Jpn Prosthodont Soc 2010; 2: 157-66.

[6] Komada W, Miura H, Okada D, et al. Study on the fracture strength of root reconstructed with post and core: alveolar bone resorbed case. Dent Mater J 2006; 25: 177-82.

[7] Okada D, Miura H, Suzuki C, et al. Stress distribution in roots restored with different types of post systems with composite resin. Dent Mater J 2008; 27: 605-11.

[8] Mannocci F, Sherriff M, Watson TF, et al. Penetration of bonding resins into fibre-reinforced composite posts: a confocal microscopic study. Int Endod J 2005; 38: 46-51.

[9] Newman MP, Yaman P, Dennison J, et al. Fracture resistance of endodontically treated teeth restored with composite posts. J Prosthet Dent 2003; 89: 360-7.

[10] Akkayan B, Gulmez T. Resistance to fracture of endodontically treated teeth restored with different post systems. J Prosthet Dent 2002; 87: 431-7.

[11] Ferrari M, Vichi A, Garcia-Godoy F. Clinical evaluation of fiberreinforced epoxy resin posts and cast post and cores. Am J Dent 2000; 13: 15B-8B.

[12] Pest BL, Cavalli G, Bertani P, et al. Adhesive post-endodontic restorations with glass fiber-reinforced epoxy resin posts: push-out tests and SEM observations. Dent Mater 2002; 18: 596-602.

[13] Willershausen B, Tekyatan H, Krummenauer F, et al. Survival rate of endodontically treated teeth in relation to conservative vs post insertion techniques -- a retrospective study. Eur J Med Res 2005; 10: 204-8.

[14] Loney RW, Moulding MB, Ritsco RG. The effect of load angulation on fracture resistance of teeth restored with cast post and cores and crowns. Int J Prosthodont 1995; 8: 247-51.

[15] Hecova H, Tzigkounakis V, Merglova V, et al. A retrospective study of 889 injured permanent teeth. Dent Traumatol 2010; 26: 466-75.

[16] Glendor U MW, Andreasen JO. Classification, epidemiology and etiology. In: Andreasen JO, Andreasen FM, Andersson L, Eds. Textbook and Color Atlas of Traumatic Injuries to the Teeth 4th ed. Oxford, Blackwell Munksgaard 2007.

[17] Skaare AB, Jacobsen I. Dental injuries in Norwegians aged 7-18 years. Dent Traumatol 2003; 19: 67-71.

[18] Levin L, Samorodnitzky GR, Schwartz-Arad D, et al. Dental and oral trauma during childhood and adolescence in Israel: occurrence, causes, and outcomes. Dent Traumatol 2007; 23: 356-9.

[19] Makade CS, Meshram GK, Warhadpande M, et al. A comparative evaluation of fracture resistance of endodontically treated teeth restored with different post core systems - an in-vitro study. J Adv Prosthodont; 2011; 3: 90-5.

[20] Bijelic J, Garoushi S, Vallittu PK, et al. Fracture load of tooth restored with glass fiber-reinforced epoxy resin post and experimental short fiber composite. Open Dent J 2011; 5: 58-65.

[21] Abo El-Ela OA, Atta OA, El-Mowafy O. Fracture resistance of anterior teeth restored with a novel nonmetallic post. J Can Dent Assoc 2008; 74: 441.

[22] Nakamura $\mathrm{T}$, Ohyama $\mathrm{T}$, Waki $\mathrm{T}$, et al. Stress analysis of endodontically treated anterior teeth restored with different types of post material. Dent Mater J 2006; 25: 145-50.

[23] Handa J, Takeda T, Kurokawa K, et al. Influence of pre-laminated material on shock absorption ability in specially designed mouthguard with hard insert and space. J Prosthodont Res 2011; 55: 214-20.

[24] Maeda M, Takeda T, Nakajima K, et al. In search of necessary mouthguard thickness. Part 1: From the viewpoint of shock absorption ability. Nihon Hotetsu Shika Gakkai Zasshi 2008; 52: 211-9.

[25] Takeda $\mathrm{T}$, Ishigami K, Handa $\mathrm{J}$, et al. Does hard insertion and space improve shock absorption ability of mouthguard? Dent Traumatol 2006; 22: 77-82.

[26] Takeda T, Ishigami K, Jun H, et al. The influence of the sensor type on the measured impact absorption of mouthguard material. Dent Traumatol 2004; 20: 29-35.

[27] Takeda T, Ishigami K, Shintaro K, et al. The influence of impact object characteristics on impact force and force absorption by mouthguard material. Dent Traumatol 2004; 20: 12-20.

[28] Satoh T. Where does the impact power applied to the human body go? J Jpn Soc Biomech 1990; 14: 68-72. 
[29] Segerstrom S, Astback J, Ekstrand KD. A retrospective long term study of teeth restored with prefabricated carbon fiber reinforced epoxy resin posts. Swed Dent J 2006; 30: 1-8.

[30] Yaman P, Thorsteinsson TS. Effect of core materials on stress distribution of posts. J Prosthet Dent 1992; 68: 416-20.

[31] Artopoulou, II, O'Keefe KL, Powers JM. Effect of core diameter and surface treatment on the retention of resin composite cores to prefabricated endodontic posts. J Prosthodont 2006; 15: 172-9.

[32] Balbosh A, Kern M. Effect of surface treatment on retention of glass-fiber endodontic posts. J Prosthet Dent 2006; 95: 218-23.

[33] Bonfante G, Kaizer OB, Pegoraro LF, et al. Fracture resistance and failure pattern of teeth submitted to internal bleaching with $37 \%$ carbamide peroxide, with application of different restorative procedures. J Appl Oral Sci 2006; 14: 247-52.

[34] Salameh Z, Sorrentino R, Ounsi HF, et al. Effect of different allceramic crown system on fracture resistance and failure pattern of endodontically treated maxillary premolars restored with and without glass glass fiber-reinforced epoxy resin posts. J Endod 2007; 33: 848-51.

[35] Baldissara P, Ozcan M, Melilli D, et al. Effect of cyclic loading on fracture strength and microleakage of a quartz fiber dowel with different adhesive, cement and resin core material combinations. Minerva Stomatol 2010; 59: 407-14.

(C) Kondoh et al.; Licensee Bentham Open.

This is an open access article licensed under the terms of the Creative Commons Attribution Non-Commercial License (http://creativecommons.org/licenses/by-nc/3.0/) which permits unrestricted, non-commercial use, distribution and reproduction in any medium, provided the work is properly cited. 